\title{
Characterization of an Electroactive Polymer for Overcharge Protection in Secondary Lithium Batteries
}

\author{
Guoying Chen, Karen E. Thomas-Alyea, John Newman and Thomas J. Richardson ${ }^{*}$ \\ Environmental Energy Technologies Division \\ Lawrence Berkeley National Laboratory \\ Berkeley, California 94720, USA
}

\begin{abstract}
The optical, electronic, and electrochemical properties of thin films of the electroactive polymer, poly(3-butylthiophene) (P3BT), were studied in a lithium hexafluorophosphate electrolyte. Upon extraction of $n$ electrons per polymer formula unit, anions are taken up to balance the charge, forming a polymer cation salt, $(\mathrm{P} 3 \mathrm{BT})^{m n+}\left(\mathrm{PF}_{6}^{-}\right)_{m n}(m$ is the number of formula units in the polymer chain), whose state of charge (SOC) varies with $n$. An in situ AC impedance method was developed to determine the electronic conductivity of the polymer at different states of charge. On oxidation of the insulating neutral P3BT polymer, the conductivity increased by eight orders of magnitude. The electrochemical potential, electronic conductivity, and optical spectrum at each state of charge were correlated, producing a color index of these primary characteristics. This allowed determination of the potential and state of charge as a function of location in transparent polymer films during propagation of an oxidation front across the film and during passage of steady-state currents through the polymer film.
\end{abstract}

* To whom correspondence should be addressed.

Tel: 510-486-8619, Fax: 510-486-8619, E-mail: tjrichardson@lbl.gov. 


\section{Introduction}

Conductive polymers have been studied extensively in recent years, and it is well known that when oxidized (also referred to as "doped" with anions) or reduced ("doped" with cations), the conductivities of these materials change dramatically and can reach as high as $10^{4} \mathrm{~S} \mathrm{~cm}^{-1}$. Their ability to switch rapidly between conductive and insulating states have made them attractive for applications in electronics and optoelectronics. ${ }^{2-7}$ Considerable effort has also been directed towards the development of conductive polymers as rechargeable battery electrodes. ${ }^{8}$ The concept of using conductive polymers as overcharge protection agents in lithium batteries is relatively new, however, and it has previously been limited to their introduction through soluble electrolyte additives. ${ }^{9-10}$ In these examples, an aromatic monomer, added to the electrolyte, is electropolymerized during overcharging of the cell, thereby creating an internal short. Although this approach may be useful for some applications, the additive may have undesirable effects on normal cell operation, hydrogen gas is generally produced during polymerization, and the internal short may not be reversible.

We have demonstrated that reliable and reversible overcharge protection can be achieved in a lithium battery by incorporating an electroactive polymer, poly(3-butylthiophene) or P3BT, within the porous separator membrane. ${ }^{11}$ Oxidation of this polymer during overcharge generates an internal short which allows an overcharge current to pass harmlessly through the cell, while the subsequent reduction of the polymer on cessation of overcharging restores the polymer to its insulating state, and allows the cell to be discharged normally. The method has proven to be effective for other conductive polymers and other cathode materials, as will be detailed in a future report. $^{12}$ 
Conversion of electroactive polymers between insulating and conducting states is

accompanied by changes in other primary characteristics, including optical properties. ${ }^{13-14}$ Here we report a detailed investigation of the redox reactions of $\mathrm{P} 3 \mathrm{BT}$ in a nonaqueous lithium electrolyte. The relationships between conductivity, potential, visible absorption spectrum, and state of charge of the polymer were determined. By constructing a color index that can uniquely identify the state of charge as a function of location in a transparent polymer film cell, we are able to understand how the internal short is established in a protected cell, why it is stable, and how it is removed when the potential drops. We are further able to visualize the potential distribution with an operating cell during oxidation of the polymer and passage of current through it.

\section{Experimental}

\section{Polymer film preparation}

Neutral poly(3-butylthiophene) with a 97\% head-to-tail regiospecific conformation (Sigma-Aldrich) was used as received. The polymer was dissolved in pure chloroform $\left(\mathrm{CHCl}_{3}\right)$ or in a mixture of $\mathrm{CHCl}_{3}$ and 5 v/o dimethylformamide (DMF) giving homogeneous $0.02 \mathrm{M}$ solutions. The films were applied by spin coating on various substrates. Except as otherwise noted, the electrolyte contained 1.0 $\mathrm{M} \mathrm{LiPF}_{6}$ in a 1:1 mixture of propylene carbonate (PC) and ethylene carbonate (EC). 


\section{In situ conductivity measurements}

The conductivity of a neutral P3BT film cast onto an insulating substrate was determined using a standard four-point probe. The thicknesses of P3BT films (20-30 $\mu \mathrm{m})$ of known weight were measured using a digital micrometer (accuracy $\pm 1 \mu \mathrm{m})$. The density of these films $(0.5 \mathrm{~g}$ $\mathrm{cm}^{-3}$ ) was then used to estimate the thickness of thinner films. For conductivity measurements on oxidized P3BT, a film, $20 \mathrm{~mm}$ long, $5 \mathrm{~mm}$ wide, and $8 \mu \mathrm{m}$ thick, was deposited by spin coating onto a flat and rigid L-shaped stainless steel plate (Fig. 1). The film was immersed in electrolyte and electrochemically oxidized in a three-electrode cell inside an inert atmosphere glove box with strips of Li foil as counter and reference electrodes. The film was charged galvanostatically beginning from the neutral state at $20 \mu \mathrm{A}$ for $100 \mathrm{~s}$ intervals. At each state of charge, the polymer potential (here referred to as OCV) was monitored during relaxation until it changed less than 10 $\mathrm{mV}$ in a $10 \mathrm{~min}$ period. The film was then removed from the electrolyte and dried. A second stainless steel plate was placed over the film and secured by clamps. The stainless steel plate with the polymer deposited on it was used as working electrode for the conductivity measurements, and the other plate as counter electrode. Impedance spectra were recorded using a Solartron 1254 Frequency Response Analyzer with SI 1286 electrochemical interface, in the frequency range between $100 \mathrm{kHz}$ and $0.1 \mathrm{~Hz}$, applying A $10 \mathrm{mV}$ sinusoidal wave. The spectrum was measured three times at each state of charge to ensure reproducibility.

\section{Optical measurements}

A neutral P3BT film with a geometric area of $4 \mathrm{~cm}^{2}$ was applied to indium tin oxide (ITO) coated glass by spin coating from a $0.02 \mathrm{M}$ solution of P3BT in $\mathrm{CHCl}_{3} / \mathrm{DMF}$. The thickness, determined from the mass of the film, was $5 \mu \mathrm{m}$. The film was immersed in electrolyte 
and oxidized galvanostatically at $50 \mu \mathrm{A}$ for $100 \mathrm{~s}$ intervals in a $10 \mathrm{~mm}$ path length cuvette with Li foil as counter and reference electrodes (Figure 2). At each state of charge, the OCV was recorded after the polymer was fully relaxed. The visible absorption spectrum between 350 and $880 \mathrm{~nm}$ was then recorded using a fiber optic CCD grating spectrometer (Ocean Optics, Inc.).

\section{Visual observation of the redox reaction in P3BT films}

The experimental set-up is shown in Figure 3a. Thin $(20 \mathrm{~nm})$ platinum electrical contacts were applied by vacuum sputtering to a glass plate as indicated by the light gray areas in the figure. A neutral P3BT film, $36 \mathrm{~mm} \times 6 \mathrm{~mm}$ and $2 \mu \mathrm{m}$ thick, was spin coated on the glass from a $0.02 \mathrm{M}$ solution in $\mathrm{CHCl}_{3} / \mathrm{DMF}$. The film covered the platinum contacts only in the shaded areas. Strips of lithium foil (125 $\mu \mathrm{m}$ thick) were placed on both sides of the polymer film to minimize the IR drop in the electrolyte. The electrolyte $\left(1 \mathrm{M} \mathrm{LiClO}_{4}\right.$ in $\left.\mathrm{PC}\right)$ was immobilized in a $150 \mu \mathrm{m}$ thick polyvinylidene difluoride (PVDF) membrane (Gelman FP Vericel), which was transparent and colorless when wetted. The membrane was placed on the top of the prepared electrodes so that the polymer film and Li foils were fully in contact with the electrolyte. Another glass plate was laid on top of the membrane, and the cell was sealed at the edges with low vapor pressure epoxy (Torr-seal, Varian Associates) before removal from the glove box.

a) Oxidation and reduction of P3BT film

To visualize the oxidation reaction, a bright light was placed under the film (area of cross section: $1.2 \times 10^{-4} \mathrm{~cm}^{2}$ ) and it was charged galvanostatically from one end. A current of $5 \mu \mathrm{A}$ (40 $\left.\mathrm{mA} \mathrm{cm}{ }^{-2}\right)$ was passed for $10 \mathrm{~min}$, then increased to $10 \mu \mathrm{A}\left(80 \mathrm{~mA} \mathrm{~cm}^{-2}\right)$ for $5 \mathrm{~min}$, and finally to $20 \mu \mathrm{A}\left(160 \mathrm{~mA} \mathrm{~cm}^{-2}\right)$. The potential was recorded at each end of the film. Images were recorded 
at 1 min intervals using an Axis Communications 2120 network camera. Subsequent reduction of the oxidized film was carried out at a current of $20 \mu \mathrm{A}\left(160 \mathrm{~mA} \mathrm{~cm}{ }^{-2}\right)$.

b) Oxidation and passage of currents through P3BT film

This experiment was carried out in a similar manner, except that the right hand end (Fig. $3 b)$ of the polymer film was connected to the Li counter electrode. A constant potential of $4.00 \mathrm{~V}$ was applied until the short was established. Thereafter, steady-state currents were passed through the film.

\section{Results and Discussion}

Preparation of conductive polymer films

Redox processes in a conductive polymer may involve dramatic macroscopic volume changes. ${ }^{15-16}$ During the oxidation process, extraction of electrons from the polymer chains alters the chain conformations (distribution of double bonds and bond angles), which generates free volume for counterions and promotes swelling. Reduction reverses the conformation changes, but the volume change is often not completely reversible. This can cause a loss of shape and integrity of a polymer film during electrochemical switching between resistive and conductive states. Some disorder in the fresh, neutral polymer is desirable because it creates a certain amount of free volume which increases its ability to accommodate the counterions.

The microstructure of a conducting polymer is directly related to sample preparation and processing, ${ }^{1}$ with electropolymerization shown to produce oxidized polymers with the highest porosity. We prepared neutral polymer films by spin coating from solutions and investigated the effects of different solvents on the properties of the films. P3BT is soluble in chloroform but has 
low solubility in polar solvents such as DMF. Both $0.02 \mathrm{M} \mathrm{CHCl}_{3}$ and $0.02 \mathrm{M} \mathrm{CHCl}_{3} / \mathrm{DMF}$ (95:5 v/o) solutions gave uniform films but with different morphologies and electrochemical behavior. As shown in Figure 4, the film from $\mathrm{CHCl}_{3}$ alone was smooth in texture, while the film deposited from the mixed solvents had greater porosity and roughness. When cycled between 1.5 and $4.0 \mathrm{~V}$, the surface of the $\mathrm{CHCl}_{3}$ film exhibited many cracks due to macroscopic volume changes during oxidation and reduction. This eventually caused the polymer to delaminate. The film prepared from the mixed solvent solution, on the other hand, remained intact during cycling. It may be that evaporation of $\mathrm{CHCl}_{3}$ from the mixed solvents resulted in rapid precipitation of the polymer due to its low solubility in DMF, resulting in a low-density deposit. In situ conductivity of P3BT films

Polymer conductivities have been reported from both ex situ ${ }^{17-22}$ and in situ measurements. ${ }^{23-29}$ The ex situ methods have typically used either a conventional four-probe approach or the more refined van der Pauw method, ${ }^{30}$ applied to electrochemically polymerized films that must be removed from the conductive substrate before measurements can be made. In situ methods are more attractive because they avoid contamination and mechanical damage due to handling and allow correlation of the conductivity with other properties such as doping level (SOC) and OCV. The few reported in situ results used either a two-probe or a four-probe approach, both of which involved construction of complex microband arrays and required electrochemical deposition of uniform, geometrically defined films extending well beyond the contacts. Measurement uncertainties and poor reproducibility of electrodeposited films are major drawbacks of these methods. In situ AC impedance spectroscopy ${ }^{31}$ allows extraction of the electrical resistance of a complex system that includes other resistance components, such as contact resistances and ionic resistances in the polymer and electrolyte. The simplicity of the 
approach makes it possible to precisely determine the conductivity of bulk polymer films with a defined geometry. The latter can be prepared using non-electrochemical methods, such as spin coating or solution casting.

In preparation of $\mathrm{P} 3 \mathrm{BT}$ films for conductivity measurements, the mass of the polymer (typically $0.4 \mathrm{mg}$ ) was carefully controlled so that the film would be thin enough to allow efficient diffusion of electrolyte through the film, but thick enough to allow observation of the bulk properties of the polymer. The conductivity of the neutral polymer was $10^{-9} \mathrm{~S} \mathrm{~cm}^{-1}$. The CV study showed that the redox reaction of P3BT was highly reversible. This permitted precise coulometric determination of the oxidation state of the polymer. The electrolyte-soaked film had an initial OCV of $3.15 \mathrm{~V}$. The time required for the film to relax after an oxidation step depended upon the conductivity (and hence, oxidation state) of the polymer: the lower the oxidation state, the longer the period (up to several hours). The OCV of the equilibrated film increased gradually with SOC, reaching $4.10 \mathrm{~V}$ for $\mathrm{SOC}=0.28$ (electrons per formula unit), corresponding to the maximum stable doping level of the polymer. This result agrees well with the reported maximum SOC of a similar polymer, poly (3-methylthiophene). ${ }^{32-33}$

During the impedance measurements, AC current passes through the stainless steel current collector, the interface between the plate and the electrolyte-filled polymer, then through the polymer-electrolyte mixture, another set of interfaces and the second current collector. Since no DC current is applied during the measurement, no net electrochemical reaction takes place. The electronic resistance of the polymer is represented by the measured difference between the real part of the impedance at low and high frequencies. ${ }^{34}$ A Nyquist plot of the impedance at each SOC is shown in Figure 5, with the $\mathrm{x}$-axis representing the real part of the impedance $\left(Z^{\prime}\right)$ and the $y$-axis the imaginary part of the impedance $\left(Z^{\prime \prime}\right)$. At low SOC $(<0.065)$, the measured 
impedance spectra show only the early portions of very large semi-circles. Because of the insulating nature of the film, the spectra did not intercept the $\mathrm{x}$-axis in the measured frequency range (Fig 5a). Increasing the SOC of the polymer by further oxidation gradually decreased the diameter of the semi-circles, and when the SOC reached 0.065, a complete semi-circle was obtained (Fig $5 b)$. Based on the known geometry and density $\left(0.5 \mathrm{~g} \mathrm{~cm}^{-3}\right)$ of the film, the conductivity of the polymer at each state of charge (SOC $>0.065)$ was derived from Figure $5 b$. The conductivities and open circuit voltages as a function of state of charge are shown in Figure 6. The conductivity increased by 8 orders of magnitude from $10^{-9} \mathrm{~S} \mathrm{~cm}^{-1}$ in the neutral state to $0.1 \mathrm{~S} \mathrm{~cm}^{-1}$ in the fully oxidized state. The conductivity vs. SOC curve exhibited a short plateau around $\mathrm{SOC}=0.10$ and a longer one centered on $\mathrm{SOC}=0.155$, then began to level off at about $\mathrm{SOC}=0.25$. While these features (and those observed in the visible spectra) are consistent with generally-accepted conduction mechanisms involving polarons and bipolarons, ${ }^{35-39}$ no attempt is made here to identify individual features.

\section{Optical properties of P3BT films}

Optical absorption spectroscopy studies have proved very useful in understanding the charge-induced changes in conjugated polymer chains, where the differences in electron energy levels are observed as optical transitions. The neutral P3BT films exhibit a broad absorption peak centered at $520 \mathrm{~nm}$ (Fig. 7), corresponding to a $\pi-\pi^{*}$ transition, as observed for many

polythiophenes. ${ }^{40}$ The band gap of the neutral polymer, estimated from the absorption edge, was $2.0 \mathrm{eV}$. As the polymer was oxidized, the absorption at $520 \mathrm{~nm}$ decreased in intensity, while a broad, new absorption centered at $750 \mathrm{~nm}$ grew until the state of charge reached 0.155 . An isosbestic point at $590 \mathrm{~nm}$ was observed in these spectra, clearly indicating a two-phase system 
(neutral polymer and polarons) in this range, and a gradual transformation of the neutral insulating phase into the more conductive phase. Similar results were reported by Łapkowski et al. for the electrochemical oxidation of poly(3,4-ethylenedioxythiophene) (PEDOT) ${ }^{41}$ When the SOC exceeded to 0.155 , the absorption intensity at $750 \mathrm{~nm}$ began to decrease and a new band appeared in the near infrared above $800 \mathrm{~nm}$. The spectra in the range above 0.155 SOC display a second isosbestic point at $780 \mathrm{~nm}$, (consistent with the transformation of polarons to bipolarons). Figure $8 \mathrm{a}$ shows the absorbance at 520 and $750 \mathrm{~nm}$ at each state of charge. These curves reach plateaus as the OCV passes through its inflection point (Fig. 8b).

\section{Color Index of SOC, Conductivity, and OCV}

Red-green-blue (RGB) values were derived from the absorbance spectra in Figure 7 by taking the percent transmission at $680 \mathrm{~nm}$ (red), $510 \mathrm{~nm}$ (green), and $440 \mathrm{~nm}$ (blue), and multiplying each by 255 . These RGB values were used to generate a color scheme for the polymer at each state of charge (Fig. 9). The neutral, insulating polymer $(\mathrm{SOC}=0)$ was bright red. Oxidation changed the polymer first to dark purple, then to dark blue, and finally to bright blue $(\mathrm{SOC}=0.25)$. Since each color corresponds to a unique $\mathrm{SOC}$, and therefore to a single $\mathrm{OCV}$ and conductivity, the index gives us a direct visual measure of the primary properties of the polymer at any location.

\section{Visual observation of redox reactions of P3BT films}

A succession of images showing the galvanostatic oxidation of the polymer film from one end is shown in Figure 10. Potentials measured at the working electrode current collector and at the open end of the film during the oxidation are shown in Figure 11. At a charging rate of 
$160 \mathrm{~mA}$ per $\mathrm{cm}^{2}$ of cross-sectional area, the oxidation front proceeded at a constant speed of about $10 \mu \mathrm{m} \mathrm{s}^{-1}$. The portion of the film behind the reaction front was dark blue, while the unoxidized region remained red, with a distinct boundary between the conductive and insulating zones. After the front reached the end of the film, the conductivity was high enough so that further oxidation took place throughout the film, gradually changing its color to light blue.

The potentials measured at the two ends of the film during the oxidation process are shown in Figure 11. At the current collector, the potential increased rapidly to a plateau whose potential depended upon the current $(3.2 \mathrm{~V}$ at $5 \mu \mathrm{A}, 3.4 \mathrm{~V}$ at $10 \mu \mathrm{A}$, and $3.6 \mathrm{~V}$ at $20 \mu \mathrm{A})$. This potential remained nearly constant until the oxidation front reached the open end of the film, then increased approximately linearly as further oxidation took place uniformly throughout the film. The potential at the open end of the film remained at the starting (neutral state) value until the arrival of the front, and then increased sharply to the same level as the current collector end. These observations support the conductive zone propagation mechanism proposed by Aoki et al., ${ }^{42-43}$ except that the presence of an electrolyte concentration gradient (neglected in their analysis) was evident in our experiment, producing the concave oxidation front.

Reduction of the oxidized film (again at $20 \mu \mathrm{A}$ ) proceeded rapidly throughout the film until the potential decreased to about $3.4 \mathrm{~V}$, transforming the entire film to a dark purple color, corresponding to a state of charge of about 0.05 . Further reduction resulted in a rapid drop in potential as the polymer near the current collector was reduced to the red neutral state, while the rest of the film slowly became dark red, indicating a state of charge of about 0.03 . Even when the potential was held at $0 \mathrm{~V}$ vs. Li for $48 \mathrm{~h}$, the bulk of the film did not return to the neutral state, due to its low conductivity. 


\section{Visual observation of film potentials during passage of current}

To visualize the behavior of the polymer as an internal overcharge protection agent in a lithium battery, the previously open end of the film was connected to the Li counter electrode. The conductive front propagated through the film in the same manner as in the previous experiment, except that once the front arrived at the Li-connected end, the cell was effectively shorted, and a steady state potential distribution was established. Figure 12a shows the appearance of the film at different current densities. The potential increased with the current, raising the bulk of the film to a higher SOC, as indicated by its color (the lighter area near the positive end is thinner than the rest of the film, but is the same color as the nearby portions). The negative end of film remained in the reduced, low conductivity state even at very high currents, but the width of the reduced portion decreased with increasing current. Detailed modeling ${ }^{44}$ of the system indicates that overcharge protection at a constant potential is achieved through the existence of this insulating region, which sustains the majority of the potential drop. This film was able to sustain a current density of $330 \mathrm{~mA} \mathrm{~cm}^{-2}$ at $4.25 \mathrm{~V}$, suggesting that even a small amount of material could carry sufficient current to prevent overcharge damage in a typical rechargeable lithium cell.

\section{Conclusions}

The primary electronic and electrochemical characteristics of $\mathrm{P} 3 \mathrm{BT}$ in a nonaqueous lithium electrolyte were determined by in situ electrochemical methods. A color index relating $\mathrm{OCV}, \mathrm{SOC}$, and conductivity was created and used to visualize the distribution of charge and potential in thin film cells. The propagation of an oxidation front through the polymer and the resistance to propagation of a reduction front allow this polymer to act as a reversible, electronic 
short to pass charge when the potential exceeds about $3 \mathrm{~V}$, while returning to a resistive state when the potential is reduced. The relationship between current density and cell potential is determined by the distribution of state of charge in the polymer, with a highly resistive region developing near the negative electrode when current is passed through the polymer. Application of this and other electroactive polymers to overcharge protection in rechargeable lithium batteries with a variety of different electrode materials will be described in subsequent publications.

\section{Acknowledgement}

This work was supported by the Assistant Secretary for Energy Efficiency and Renewable Energy, Office of FreedomCAR and Vehicle Technologies of the U. S. Department of Energy under Contract No. DE-AC03-76SF00098. 


\section{References}

1 R. Menon, C. O. Yoon, D. Moses, A. J. Heeger, in: T. A. Skotheim, R. L. Elsenbaumer and J. R. Reynolds (Ed.), Handbook of Conducting Polymers, $2^{\text {nd }}$ ed., Marcel Dekker, New York, 1998, p. 27.

2 J. H. Burroughes, C. A. Jones, R. H. Friend, Nature 335 (1988) 137.

3 A. Dodabalapur, H. E. Katz, L. Torsi, R. C. Haddon, Science 269 (1995) 560.

4 J. J. Halls, C. A. Walsh, N. C. Greenham, E. A. Marseglia, R. H. Frend, S. C. Moralli, A. B. Homes, Nature 376 (1995) 498.

5 Q. Pei, G. Yu, C. Zhang, Y. Yang, A. J. Heeger, Science 269 (1995) 1086.

6 M. K. Ram, N. S. Sundaresn, B. D. Malhotra, J. Phy. Chem. 97 (1993) 1580.

7 P. Novák, K. Müller, K. S. V. Santhanam, O. Haas, Chem. Rev. 97 (1997) 207.

8 B. Scrosati (Ed.), Application of Electroactive Polymers, Chapman \& Hall, London, 1993.

9 F. R. Denton, J. N. Howard, A. A. Anani, J. M. Fernandez, US Patent 6,228,516 (Motorola).

10 H. Mao, D. S. Wainwright, US Patent 6,074,776 (Moli Energy Limited).

11 G. Chen, T. J. Richardson, Electrochem. Solid State Lett. 7 (2004) A23.

12 G. Chen, K. E. Thomas-Alyea, J. Newman, T. J. Richardson, in preparation.

13 J. Roncali, Chem. Rev. 92 (1992) 711.

14 A. O. Patil, A. J. Heeger, F. Wudl, Chem. Rev. 88 (1988) 183.

15 T. F. Otero, H. Grande, J. Rodríguez, J. Phys. Chem. B 101 (1997) 8525.

16 H. Grande, T. F. Otero, J. Phys. Chem. B 102 (1998) 7535.

17 J. Langer, Solid State Commun. 25 (1978) 839.

18 A. J. Epstein, J. M. Ginder, F. Zuo, H. -S. Woo, D. B. Tanner, A. F. Richter, M. Angelopoulos, W. -S. Huang, A. G. MacDiarmid, Synth. Met. 21 (1987) 63. 
19 T. Hagiwara, M. Yamaura, K. Sata, M. Hirromoto, K. Iwata, Synth. Met. 32 (1989) 367.

20 A. Kitani, J. Izumi, J. Yano, Y. Hiromoto, K. Sasaki, Bull. Chem. Soc. Jpn. 57 (1984) 2254.

21 M. Ogasawara, K. Gunahashi, T. Demura, T. Hagiwara, K. Iwata, Synth. Met. 14 (1986) 61.

22 P. Snauwaert, R. Lazzaroni, J. Riga, J. J. Verbist, Synth. Met. 21 (1987) 181.

23 B. J. Feldman, P. Burgmayer, R. W. Murray, J. Am. Chem. Soc. 107 (1985) 872.

24 E. M. Geniès, P. Hany, M. Lapkowski, C. Santier, L. Olmedo, Synth. Met. 25 (1988) 29.

25 L. Olmedo, I. Chanteloube, A. Germain, M. Petit, E. M. Geniès, Synth. Met. 30 (1989) 159.

26 G. Schiavon, S. Sitran, G. Zotti, Synth. Met. 32 (1989) 209.

27 G. P. Kittlesen, H. S. White, M. S. Wrighton, J. Am. Chem. Soc. 106 (1984) 7389.

28 J. W. Thackeray, H. S. White, M. S. Wrighton, J. Phys. Chem. 89 (1985) 5133.

29 E. W. Paul, A. J. Ricco, M. S. Wrighton, J. Phys. Chem. 89 (1985) 1441.

30 J. Lange, J. Appl. Phys. 35 (1964) 2659.

31 S. H. Glarum, J. H. Marshall, J. Electrochem. Soc. 134 (1987) 142.

32 A. N. Chowdhury, Y. Harima, Y. Kunugi, K. Yamashita, Electrochim. Acta. 41 (1996) 1993.

33 Z. W. Sun, A. J. Frank, J. Chem. Phys. 94 (1991) 4600.

34 A. J. Bard, L. R. Faulkner (Ed.), Electrochemical Methods, Fundamentals and Applications, $2^{\text {nd }}$ ed., John Wiley \& Sons, 2001, p.368.

40 C. Visy, J. Lukkan, J. Kankare, Synth. Met. 69 (1995) 319.

41 M. Łapkowske, A. Proń, Synth. Met. 110 (2000) 79.

42 Y. Tezuka, K. Aoki, K. Shinozaki, Synth. Met. 30 (1989) 369.

43 Y. Tezuka, K. Aoki, T. Ishii, Electrochimica Acta. 44 (1999) 1871.

44 K. E. Thomas-Alyea, J. Newman, G. Chen, T. J. Richardson, J. Electrochem. Soc. 151 (2004) A509. 


\section{Figure captions}

1. Schematic of the in situ conductivity measurements.

2. Schematic of the in situ optical measurements.

3. Schematic of the visual observation experiments of the redox reaction of P3BT a) redox reaction of the film with an open end; b) redox reaction with one end of the film connected to the Li counter electrode.

4. SEM images of spin coated P3BT films on a stainless steel plate: a) from a $0.02 \mathrm{M} \mathrm{CHCl}_{3}$ solution; b) from a $0.02 \mathrm{M} \mathrm{CHCl}_{3} / \mathrm{DMF}(95: 5 \mathrm{v} / \mathrm{o})$ solution.

5. Nyquist plots of the in situ impedance measurements of P3BT films at the indicated state of charge: a) SOC $<0.065$; b) SOC $>0.065$.

6. In situ conductivities and open circuit voltages of P3BT as a function of state of charge.

7. Optical spectra of a P3BT film as a function of state of charge: a) 0 ; b) 0.0163 ; c) 0.0408 ; d) 0.0734 ; e) 0.106 ; f) 0.139 ; g) 0.155 ; h) 0.188 ; i) 0.22 ; j) 0.25 electrons per formula unit.

8. a) Absorbance of P3BT at 520 and $750 \mathrm{~nm}$ vs. SOC; b) open circuit voltage of P3BT vs. SOC.

9. Color index of SOC, OCV and conductivity of P3BT.

10. Progress of oxidation front through P3BT film.

11. Potentials vs. time at current collector and open end during oxidation of P3BT film.

12. a) Visualization of steady-state potential distribution in P3BT film at different current densities; b) current density vs. potential across the film. 


\section{Chen et al. Figure 1}

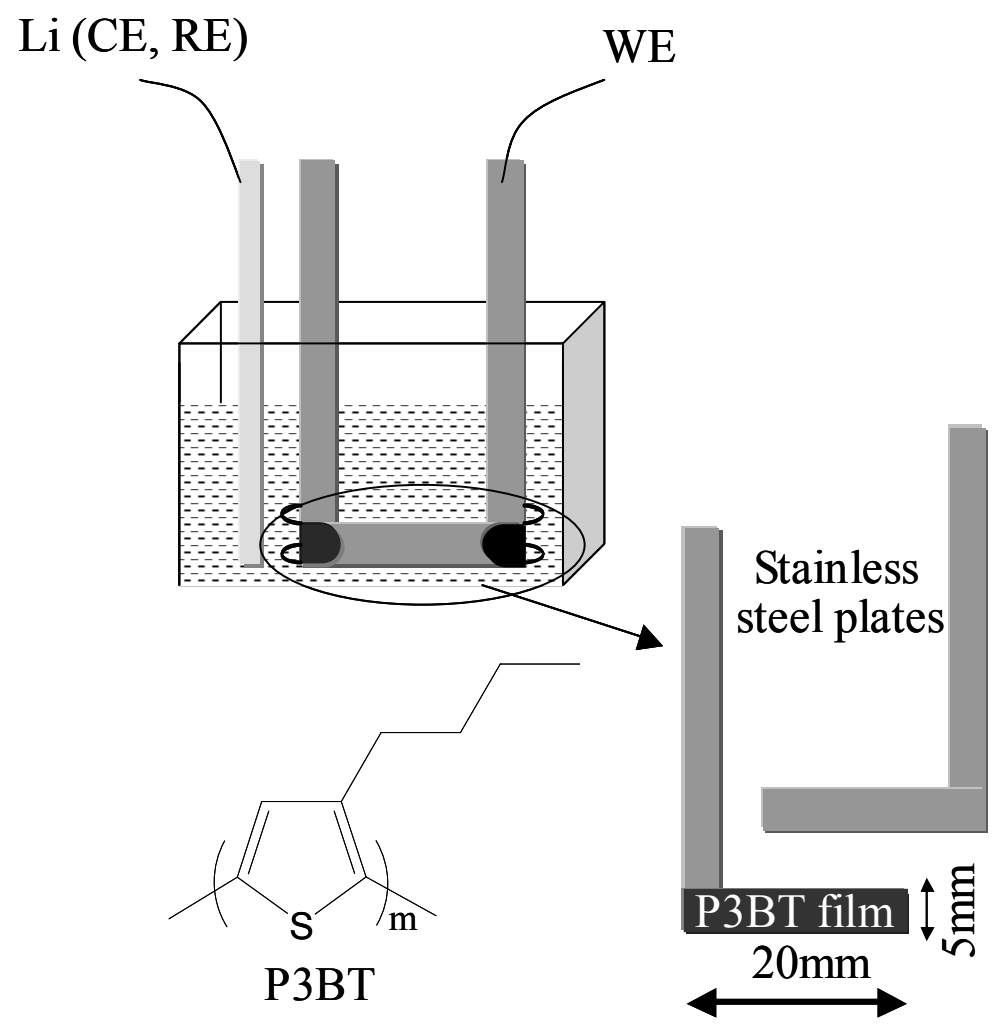


Chen et al. Figure 2

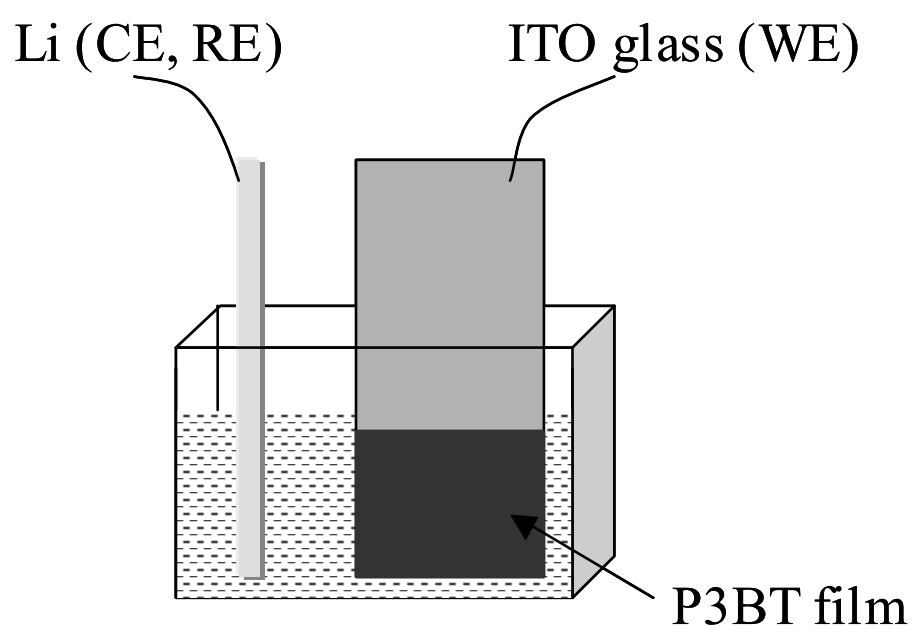




\section{Chen et al. Figure 3}

(a)

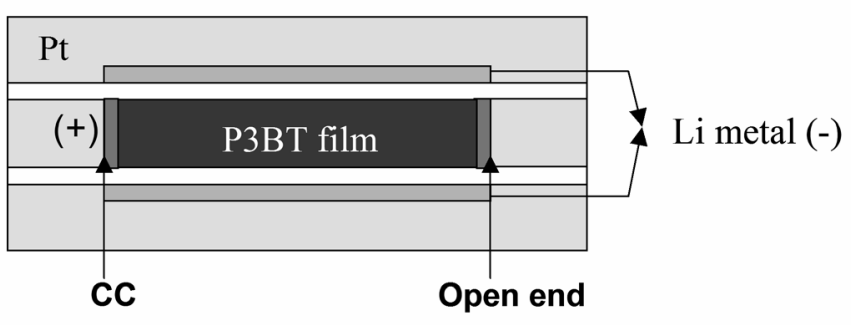

(b)

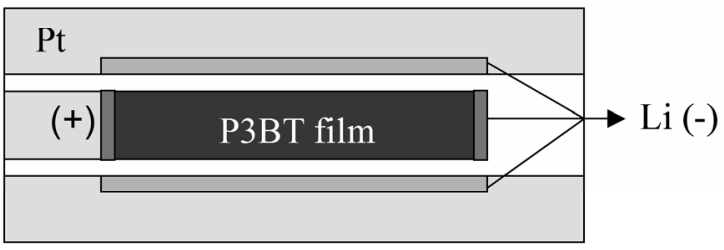


Chen et al. Figure 4
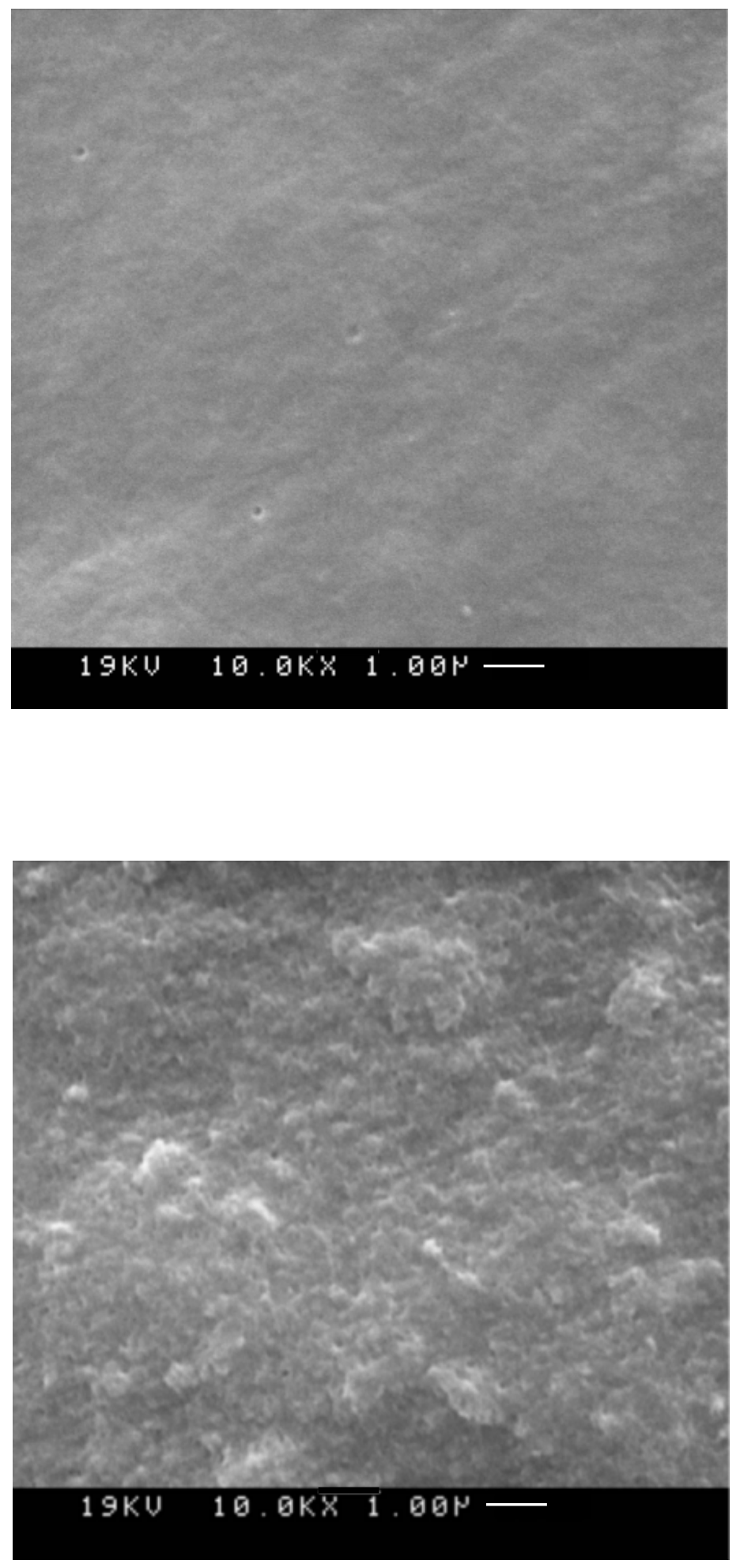


\section{Chen et al. Figure 5}
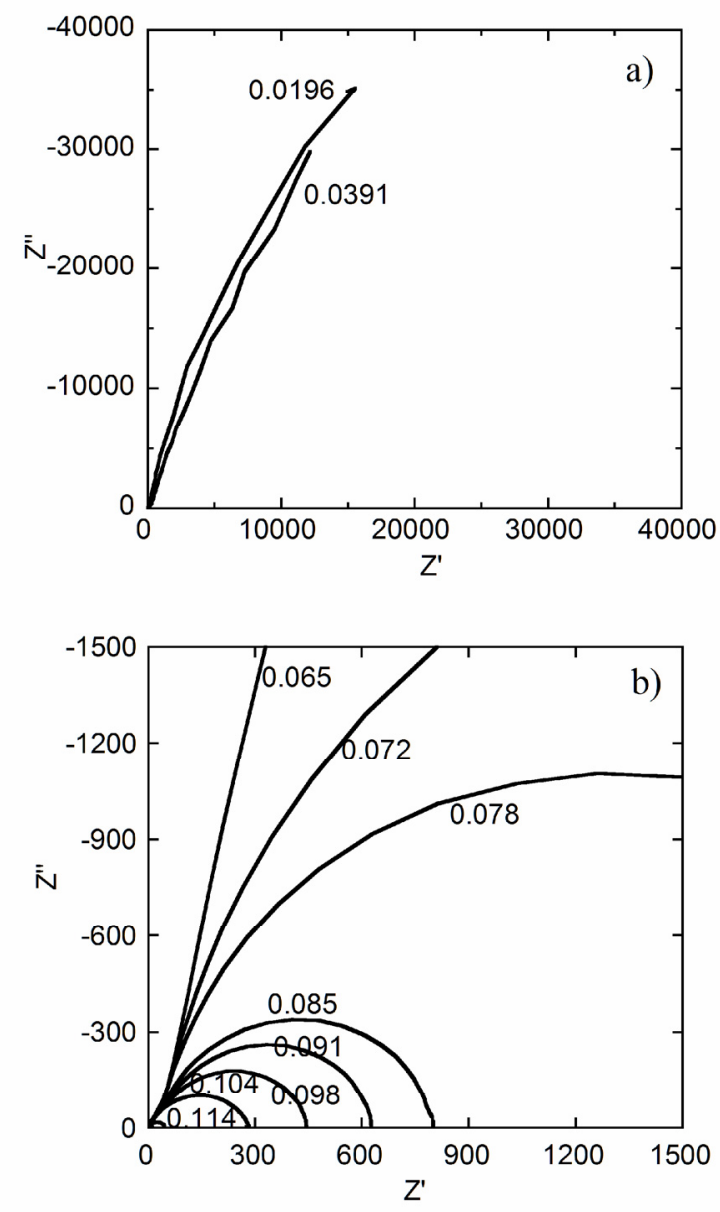
Chen et al. Figure 6

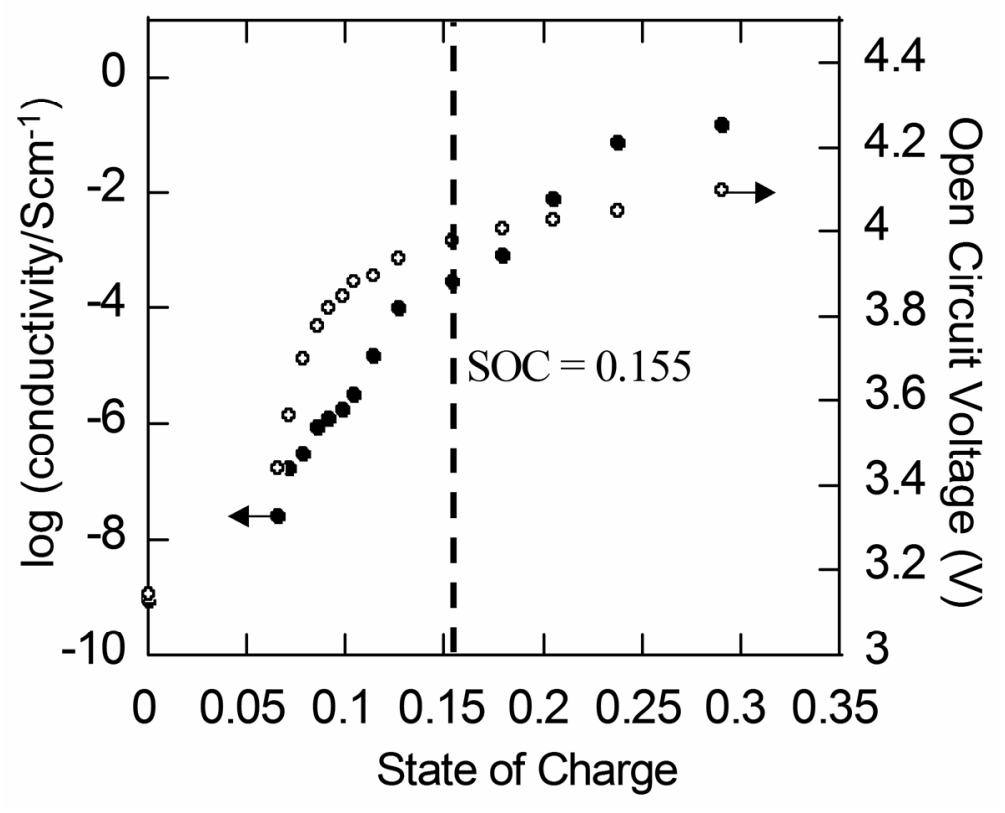




\section{Chen et al. Figure 7}

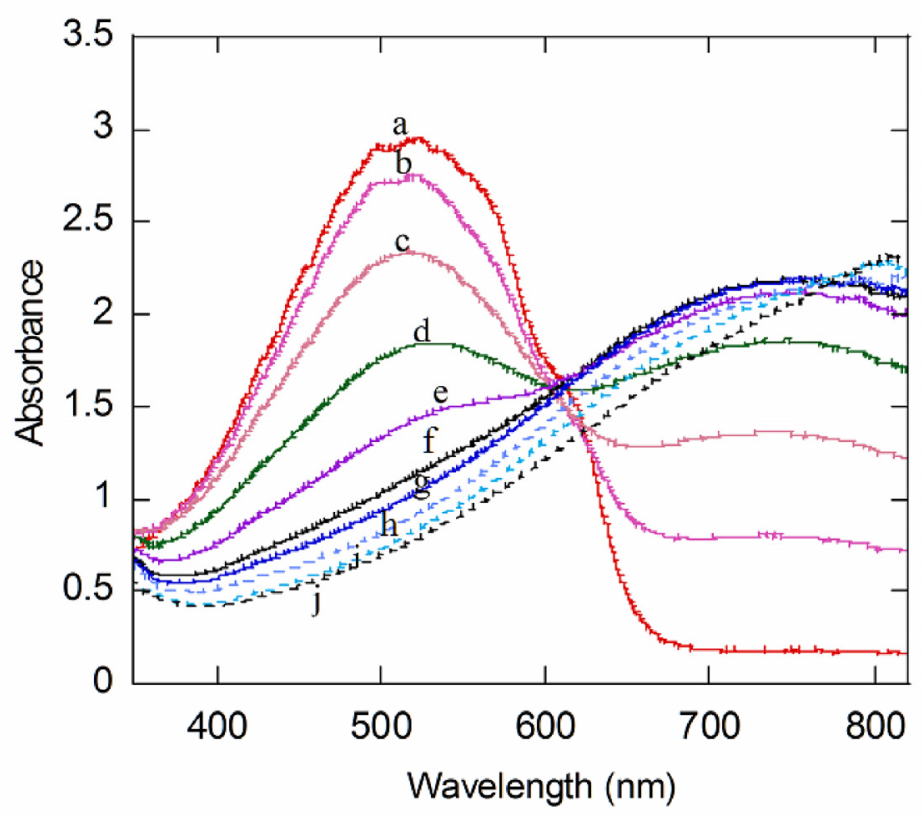




\section{Chen et al. Figure 8}
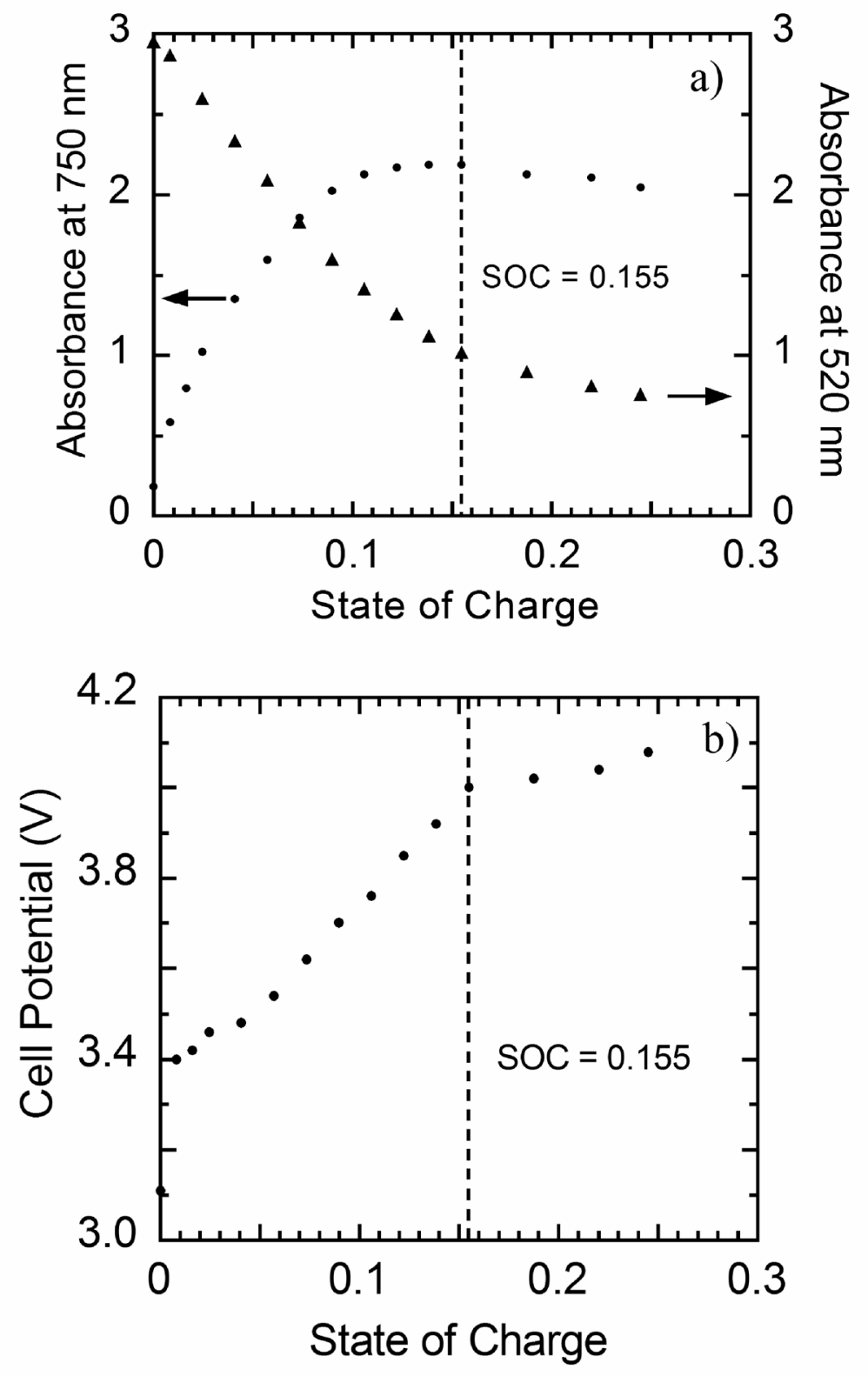
Chen et al. Figure 9

\begin{tabular}{|c|c|c|}
\hline $\mathrm{SOC}$ & $\operatorname{OCV}(\mathrm{V})$ & Conductivity $(\mathrm{S} / \mathrm{cm})$ \\
\hline 0.245 & 4.08 & 0.1 \\
\hline 0.22 & 4.04 & 4 \\
\hline 0.188 & 4.02 & \\
\hline 0.139 & 3.92 & \\
\hline 0.106 & 3.76 & \\
\hline 0.0897 & 3.70 & \\
\hline 0.0734 & 3.62 & \\
\hline 0.0571 & 3.54 & \\
\hline 0.0408 & 3.48 & \\
\hline 0.0245 & 3.46 & \\
\hline 0.0163 & 3.42 & \\
\hline 0 & 3.11 & $1.0 \times 10^{-9}$ \\
\hline
\end{tabular}


Chen et al. Figure 10

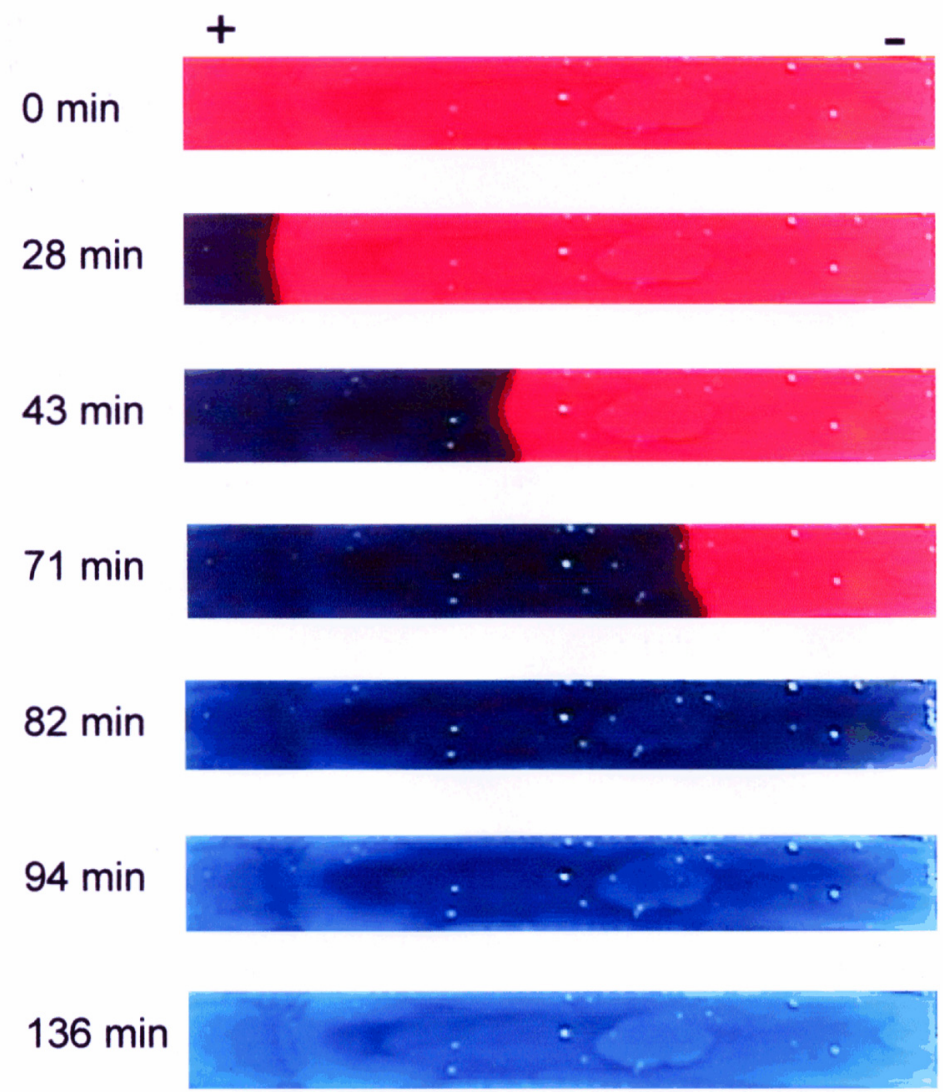




\section{Chen et al. Figure 11}

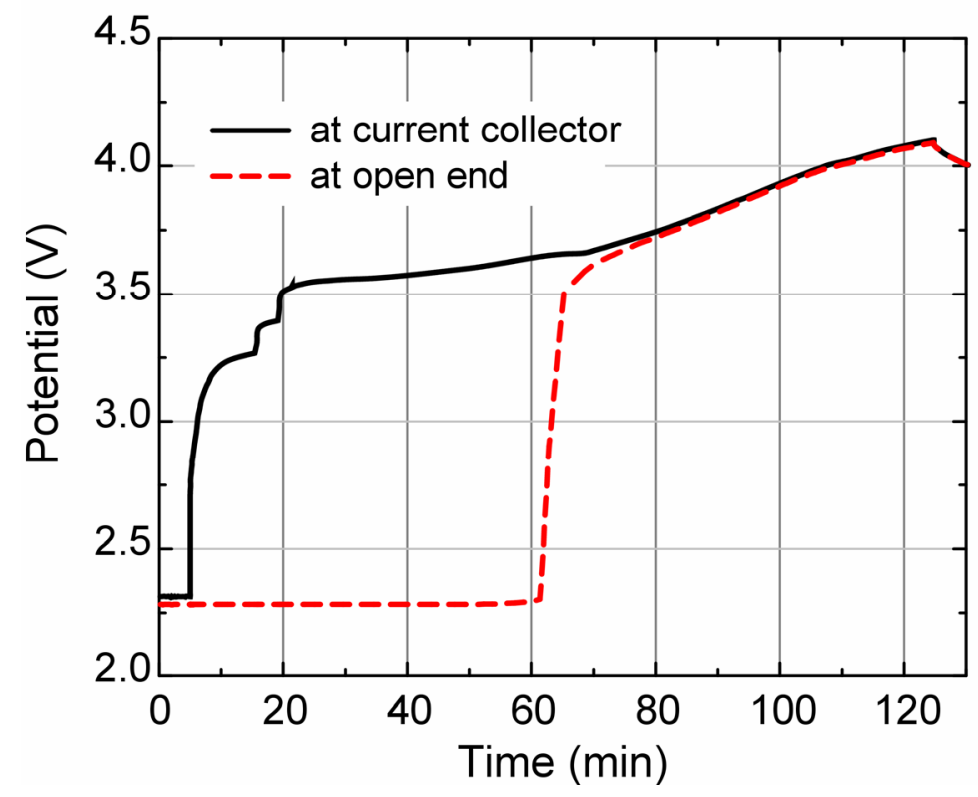




\section{Chen et al. Figure 12}

a) Current Density $\left(\mathrm{mA} / \mathrm{cm}^{2}\right)$

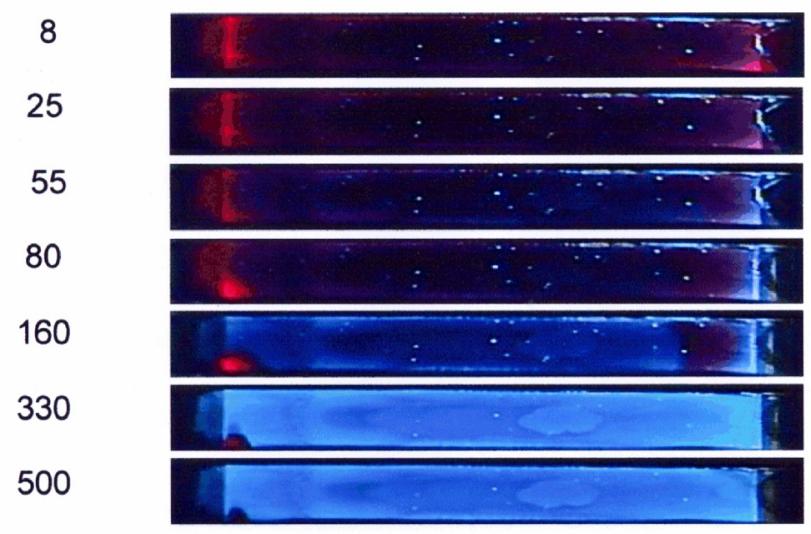

b)

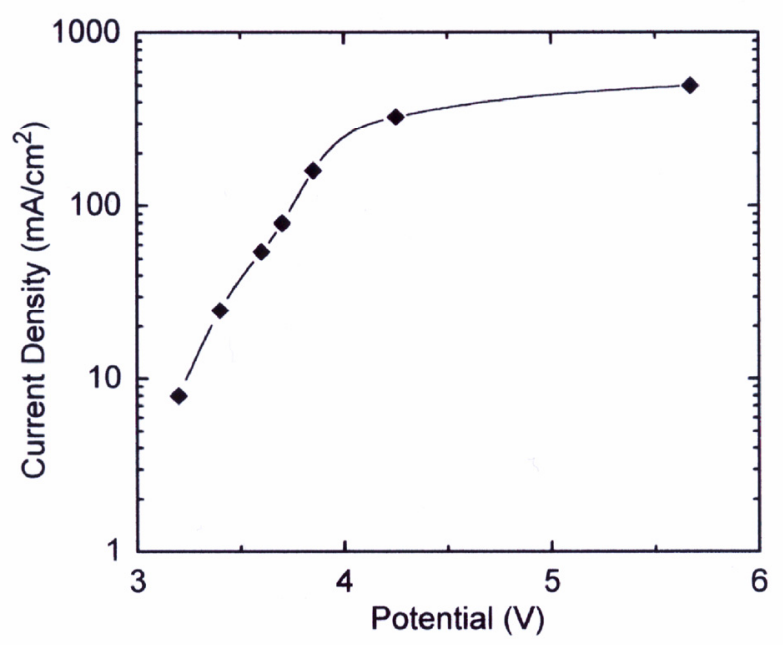

